University of Nebraska - Lincoln

DigitalCommons@University of Nebraska - Lincoln

2010

\title{
Chemisorption of a thiol-functionalized ruthenium dye on zinc oxide nanoparticles: Implications for dye-sensitized solar cells
}

\author{
Jagdeep Singh \\ University of Massachusetts - Lowell \\ Jisun Im \\ University of Massachusetts - Lowell \\ James E. Whitten \\ University of Massachusetts - Lowell, James_Whitten@uml.edu \\ Jason W. Soares \\ US Army Natick Soldier Research \\ Diane M. Steeves \\ US Army Natick Soldier Research, diane.steeves@us.army.mil
}

Follow this and additional works at: https://digitalcommons.unl.edu/usarmyresearch

Part of the Operations Research, Systems Engineering and Industrial Engineering Commons

Singh, Jagdeep; Im, Jisun; Whitten, James E.; Soares, Jason W.; and Steeves, Diane M., "Chemisorption of a thiol-functionalized ruthenium dye on zinc oxide nanoparticles: Implications for dye-sensitized solar cells" (2010). US Army Research. 154.

https://digitalcommons.unl.edu/usarmyresearch/154

This Article is brought to you for free and open access by the U.S. Department of Defense at DigitalCommons@University of Nebraska - Lincoln. It has been accepted for inclusion in US Army Research by an authorized administrator of DigitalCommons@University of Nebraska - Lincoln. 


\title{
Chemisorption of a thiol-functionalized ruthenium dye on zinc oxide nanoparticles: Implications for dye-sensitized solar cells
}

\author{
Jagdeep Singh ${ }^{a}$, Jisun Im ${ }^{a}$, James E. Whitten ${ }^{a,}{ }^{*}$, Jason W. Soares ${ }^{b}$, Diane M. Steeves ${ }^{b, * *}$ \\ a Department of Chemistry, Center for Advanced Materials, and Center for High-Rate Nanomanufacturing, The University of Massachusetts Lowell, Lowell, MA 01854, USA \\ ${ }^{\mathrm{b}}$ US Army Natick Soldier Research, Development and Engineering Center, Natick, MA 01760, USA
}

\section{A R T I C L E I N F O}

\section{Article history:}

Received 1 June 2010

In final form 8 August 2010

Available online 12 August 2010

\begin{abstract}
A B S T R A C T
$\mathrm{ZnO}$ is an alternative to $\mathrm{TiO}_{2}$-based dye-sensitized solar cells (DSSCs). Adsorption of cis-rutheniumbis[2,2'-bipyridine]-bis[4-thiopyridine] onto ZnO nanorods has been studied using X-ray and ultraviolet photoelectron spectroscopies (XPS and UPS). XPS indicates chemisorption with a surface density of ca. $1 \times 10^{15}$ molecules $/ \mathrm{cm}^{2}$, confirming the possibility of using thiol-terminated dyes for ZnO-based DSSC devices. The energy level diagram, based on UPS and absorbance spectroscopy, indicates that the LUMO of this dye is lower in energy than the $\mathrm{ZnO}$ conduction band edge, providing minimal enthalpic driving force for photovoltaic electron injection. However, optimization of thiol-functionalized Ru dyes could result in competitive $\mathrm{ZnO}$-based DSSCs.
\end{abstract}

(C) 2010 Elsevier B.V. All rights reserved.

\section{Introduction}

Leading organic photovoltaic technologies include conjugated polymer [1,2] and dye-sensitized solar cells (DSSCs) [3]. The latter contain dye-coated metal oxide electrodes, with titanium dioxide most commonly used. Its advantages include processability into high surface area nanocrystalline electrodes [4], covalent attachment of dyes via carboxylate, phosphonate, and hydroxylate linkers [5-8], and energy level matching with adsorbed dyes for efficient electron ejection $[9,10]$. In the latter case, it is desirable for the conduction band of the metal oxide to be at an optimal energy relative to the lowest unoccupied molecular orbital (LUMO) of the dye.

Titanium dioxide-based DSSCs have shown tremendous promise, with conversion efficiencies greater than $11 \%$ [5]. Jose et al. [11] reviewed the use of other metal oxide electrodes that could potentially lead to greater efficiencies. Zinc oxide and titanium dioxide are wide gap semiconductors with bandgaps of ca. $3.2 \mathrm{eV}$. However, a potential advantage of $\mathrm{ZnO}$ over $\mathrm{TiO}_{2}$ is that its electron mobility is greater than that of commonly used anatase $\mathrm{TiO}_{2}[11,12]$.

Various experiments, including ones in our laboratories, have demonstrated that underivatized alkanethiols chemisorb onto zinc oxide [13-21], and quantum mechanical modeling confirms chemisorption [22]. In contrast, however, FTIR measurements on $\mathrm{ZnO}$ nanotips indicate an absence of hexanethiol adsorption [23].

\footnotetext{
${ }^{*}$ Corresponding author. Fax: +1 9789343013.

** Corresponding author. Fax: +1 5082335521.

E-mail addresses: James_Whitten@uml.edu (J.E. Whitten), diane.steeves@us. army.mil (D.M. Steeves).
}

While it is clear in the case of $\mathrm{TiO}_{2}$ that carboxylate and phosphonate linkers are suitable for DSSC applications, chemistries to attach dyes to nanoparticulate $\mathrm{ZnO}$ are much less developed.

While a variety of studies have investigated the bonding of Ru-based dyes to $\mathrm{TiO}_{2}$ via carboxylic acid groups, very little work has been performed related to dye adsorption on $\mathrm{ZnO}$. Ohlsson et al. [24] compared the affinity of variously functionalized dyes to $\mathrm{TiO}_{2}$ and $\mathrm{ZnO}$ electrodes. Using UV-vis spectroscopy, they found that 4-phenylazo-benzenethiol and cis-ruthenium-bis[2,2'-bipyridine]-bis[4-thiopyridine] exhibited greater adsorption on $\mathrm{ZnO}$ than on $\mathrm{TiO}_{2}$. They also measured greater adsorption of thiol-functionalized dyes on $\mathrm{ZnO}$ compared to carboxylic acid-functionalized dyes. No spectroscopic information or conclusions were provided on how the dyes bonded to the $\mathrm{ZnO}$ electrodes.

Using X-ray photoelectron spectroscopy (XPS), this Letter provides the first spectroscopic proof that thiol-derivatized $\mathrm{Ru}(\mathrm{II})$ dyes chemisorb on $\mathrm{ZnO}$ nanoparticles via $\mathrm{Zn}-\mathrm{S}$ bonds and demonstrates that they adsorb with adequate packing density to make them useful for DSSC applications. Ultraviolet photoelectron spectroscopy (UPS) is used to determine the work function of $\mathrm{ZnO}$ functionalized with cis-ruthenium-bis[2,2'-bipyridine]-bis[4-thiopyridine] and the ionization energy of the highest occupied molecular orbital (HOMO) of the adsorbed dye. The resulting energy level diagram indicates that the LUMO lies at a lower energy than the $\mathrm{ZnO}$ conduction band edge. Implications of this with respect to DSSC performance are discussed.

\section{Experimental}

The thiol-derivatized $\mathrm{Ru}$ dye, cis-ruthenium-bis[2,2'-bipyridine]-bis[4-thiopyridine], was synthesized according to Ref. [24]. 
ZnO nanorods (Nanocerox, Inc.), with typical diameters of 50$100 \mathrm{~nm}$ and lengths of $100-700 \mathrm{~nm}$, were dried overnight in vacuum at $200{ }^{\circ} \mathrm{C}$. Three hundred and fifty milligrams of the dried nanorods were suspended by ultrasonication in $40 \mathrm{ml}$ of $95 \%$ ethanol $/ 5 \% \mathrm{H}_{2} \mathrm{O}$ for $10 \mathrm{~min}$. Three hundred and fifty milligrams of the dye was added while stirring the suspension under argon, and it was stirred for an additional hour. The product was collected by filtration, washed with $300 \mathrm{ml}$ of $100 \%$ ethanol, dried at $110{ }^{\circ} \mathrm{C}$ for $10 \mathrm{~min}$, and stored in a desiccator. Control $\mathrm{ZnO}$ samples, without the addition of $\mathrm{Ru}$ dye, were prepared using the same procedure.

Samples for XPS and UPS were prepared by dispersing $60 \mathrm{mg}$ of dye-functionalized or control $\mathrm{ZnO}$ in $30 \mathrm{ml}$ of $95 \%$ ethanol/5\% water and ultrasonicating for $5 \mathrm{~min}$. This was then poured onto a copper coupon $\left(1 \mathrm{~cm}^{2}\right.$, pre-cleaned with dilute hydrochloric acid, methanol, and distilled water) in a Gooch crucible. The solution was allowed to evaporate/drain through the crucible overnight, resulting in a uniform coating. The coupons were attached to sample stubs using electrically conductive silver paint. For UPS of the $\mathrm{Ru}$ dye (without $\mathrm{ZnO}$ ), the sample was prepared by spin-coating an indium tin oxide (ITO) substrate with a $1 \mathrm{mg} / \mathrm{ml}$ ethanolic solution at $1000 \mathrm{rpm}$ for $60 \mathrm{~s}$. This gave a film thickness of 200-400 $\AA$, as determined from profilometry.

Details of the XPS and UPS experiments using MgK $\alpha$ X-rays $(h v=1253.6 \mathrm{eV})$ and He I light $(h v=21.22 \mathrm{eV})$ have been previously described $[20,25]$. Photoelectrons were detected normal to the sample, and pass energies of 5 and $20 \mathrm{eV}$ were used for UPS and XPS, respectively. The HOMO-LUMO gap was determined by measuring the long wavelength threshold of the UV-vis absorbance spectrum of a spin-coated Ru dye film on a quartz slide, with a clean quartz slide used as a reference. In this case, the Ru dye was spin-coated twice at $800 \mathrm{rpm}$ for $60 \mathrm{~s}$ using a $20 \mathrm{mg} / \mathrm{ml}$ ethanolic solution.

\section{Results and discussion}

Figure 1 shows XPS of the S2p region of the thiol-functionalized $\mathrm{Ru}$ dye adsorbed on $\mathrm{ZnO}$ and 1-dodecanethiol on $\mathrm{ZnO}$. The latter

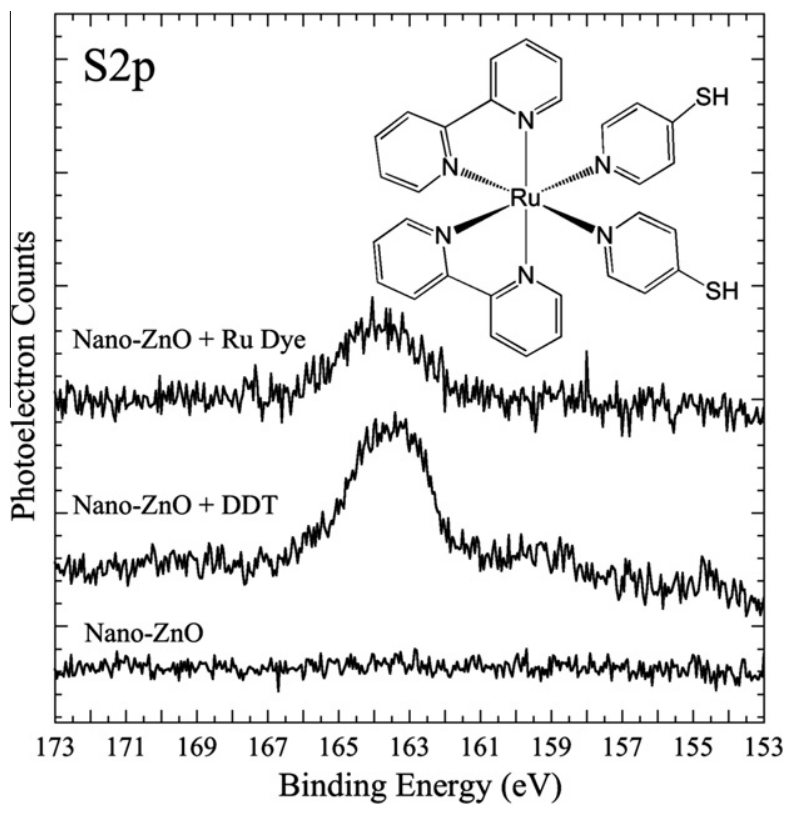

Figure 1. MgKa XPS of the S2p region of $\mathrm{ZnO}$ (control), 1-dodecanethiol (DDT) functionalized $\mathrm{ZnO}$, and $\mathrm{Ru}$ dye-functionalized $\mathrm{ZnO}$. The chemical structure of the thiol-derivatized dye is included. sample was prepared as described in Ref. [20]. In both cases, the peak binding energy is $163.6 \mathrm{eV}$, indicating that the thiol groups bind similarly. Alkanethiols, such as DDT, are known to bind to zinc oxide via formation of $\mathrm{Zn}-\mathrm{S}$ bonds [20], and it is concluded that the dye binds to the nanorods via these covalent linkages. Elemental analysis of the ZnO/Ru dye films using C1s, S2p, N1s and Ru3d transitions yields $\mathrm{C} / \mathrm{S}, \mathrm{S} / \mathrm{Ru}$, and $\mathrm{N} / \mathrm{S}$ atomic ratios of $28 \pm 3,2.1 \pm 0.2$, and $3.1 \pm 0.3$, respectively. Except for the high carbon content due to adventitious carbon, these are consistent with the expected ratios. The $S / Z n$ atomic ratio, obtained from the $S 2 p$ and $\mathrm{Zn} 3 \mathrm{p}$ transitions, is $0.07 \pm 0.01$. Experiments, using the same type of $\mathrm{ZnO}$ nanorods, indicate that saturation monolayer coverage of methanethiol and 1-dodecanethiol has an S/Zn ratio of $0.14 \pm 0.1$ [20]. These results demonstrate that the dye adsorbs on the $\mathrm{ZnO}$ nanorods at half the thiol group coverage, undoubtedly due to its larger size. Assuming that 1 -dodecanethiol adsorbs with a similar packing density as 1-octadecanethiol [18] on oxidized $\mathrm{Zn}$, an approximate surface density of $1 \times 10^{15} / \mathrm{cm}^{2}$ of dye molecules is indicated. This is similar in density to thiols self-assembled on $\mathrm{Au}\left(\begin{array}{lll}1 & 1 & 1\end{array}\right)$ [26] and is consistent with adsorption not being on minority sites. Furthermore, it is larger than the coverage of $\mathrm{Ru}(\mathrm{II})$ bipyridine complexes adsorbed on polycrystalline anatase $\mathrm{TiO}_{2}$, reported to be ca. $9 \times 10^{-11} \mathrm{~mol} / \mathrm{cm}^{2}$ (i.e., $5 \times 10^{13}$ molecules $/ \mathrm{cm}^{2}$ ) [27].

Figure 2 displays UPS spectra of the Ru dye-functionalized $\mathrm{ZnO}$ nanoparticle sample, a $\mathrm{ZnO}$ control and spin-coated Ru dye. In all cases, the large peak in the energy range of $19-21 \mathrm{eV}$ is due to nonspecific secondary electrons. For the $\mathrm{ZnO}$ control, no peaks are observed below $8 \mathrm{eV}$, but the ionization threshold (work function) is $6.9 \pm 0.2 \mathrm{eV}$. For the Ru dye-functionalized $\mathrm{ZnO}$ sample, a broad feature is observed at ca. $6.8 \mathrm{eV}$, with a threshold (HOMO edge) of $6.0 \pm 0.2 \mathrm{eV}$. The spin-coated dye has distinct valence features at 6.9 and $8.2 \mathrm{eV}$. The HOMO contains strong contributions from the Ru orbitals, as discussed for related dyes [28]. UPS yields the energies of the valence states but does not directly give the energies of unoccupied orbitals. As for other bipyridine-containing Ru dyes, the lowest energy unoccupied states are expected to consist of contributions from the bipyridine $\pi$ orbitals [29]. The LUMO energy may be estimated by combining the HOMO-LUMO gap with the HOMO threshold.

Figure 3 shows the UV-vis absorption spectrum of the Ru dye film with maxima at $298 \mathrm{~nm}(4.1 \mathrm{eV})$ and $420 \mathrm{~nm}(2.9 \mathrm{eV})$. The spectrum contains several peaks, including one having $\lambda_{\max }$ at $420 \mathrm{~nm}(2.9 \mathrm{eV})$. This is likely not the metal-to-ligand charge transfer (MLCT) transition, consisting of excitation from the Ru $4 \mathrm{~d}$ to ligand $\pi^{*}$ orbitals, since this normally occurs at longer wavelengths for bipyridyl-containing Ru-based dyes $[25,30]$. The MLCT transition is evidently not fully resolved and is contained in the broad band at longer wavelengths, with its maximum in the shoulder near $550 \mathrm{~nm}(2.2 \mathrm{eV})$. The long wavelength threshold, approximating the dye's HOMO-LUMO gap, is $657 \pm 5 \mathrm{~nm}(1.9 \mathrm{eV})$. Note that there are some assumptions in equating this threshold with the bandgap. Firstly, it would be preferable to use the UV-vis spectrum for dye adsorbed on $\mathrm{ZnO}$; attempts to obtain a reliable backgroundcorrected spectrum failed because of difficulty in preparing a reference with exactly the same $\mathrm{ZnO}$ thickness. However, recent theoretical work by De Angelis et al. [31] has investigated the HOMO-LUMO gap of isolated Ru(II)-polypyridyl molecular dyes compared to ones interacting with nanoparticulate titanium dioxide. The results indicate that estimates of energy level alignment for non-interacting dye and $\mathrm{TiO}_{2}$ are similar to those for the coupled system. Assuming a similar situation holds for the dye and $\mathrm{ZnO}$, the error involved in using the dye film to estimate the HOMO-LUMO gap is minimal. A second assumption is that the optical bandgap is identical to the actual HOMO-LUMO gap. The latter is somewhat larger since it accounts for electron-hole interaction of the excited dye [32,33]. 

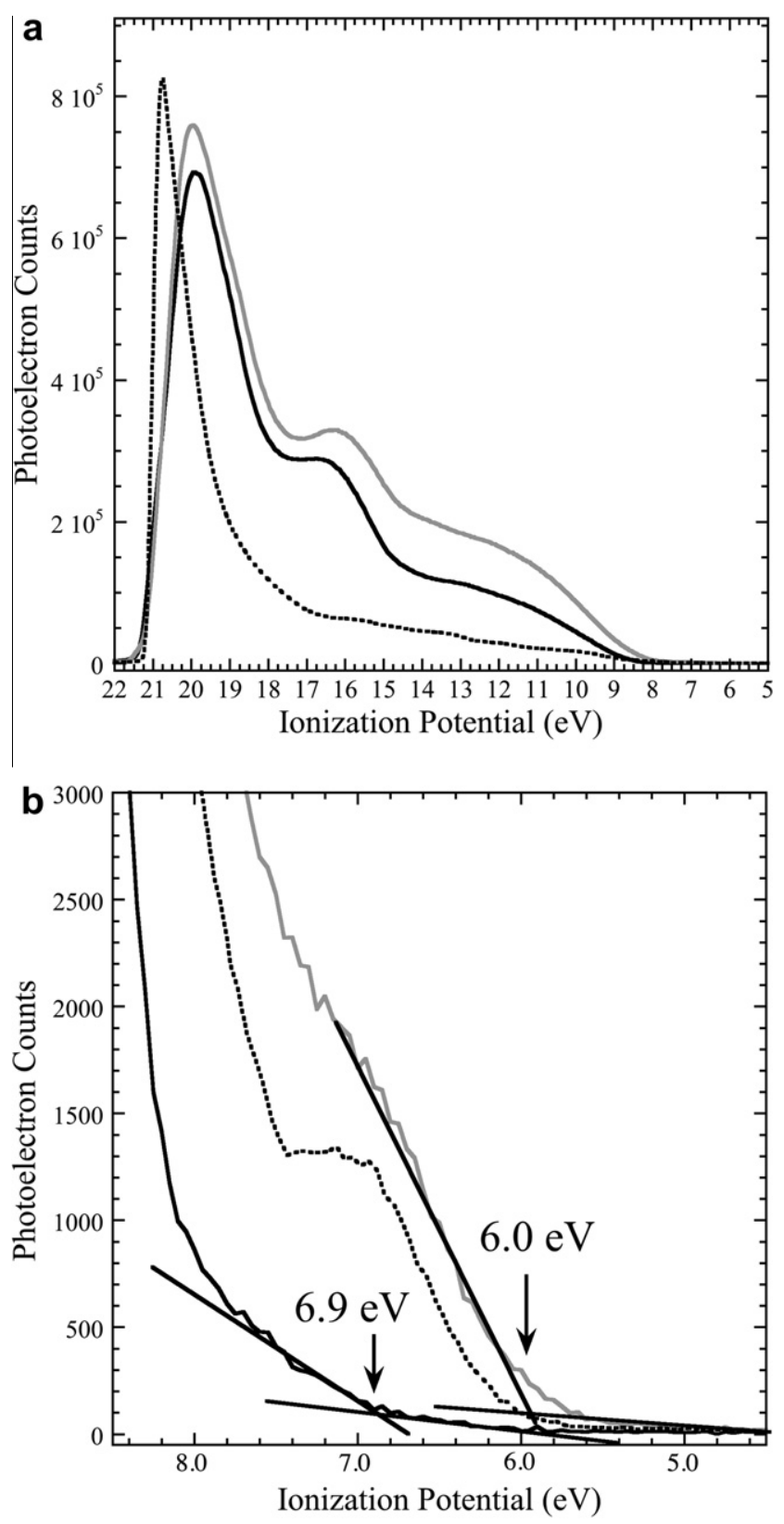

Figure 2. He I UPS of unfunctionalized ZnO (darker curve), Ru dye-functionalized $\mathrm{ZnO}$ (lighter curve), and a spin-coated film of the Ru dye (dashed curve). The spectra are plotted with respect to the ionization energy. Zero on this scale corresponds to the vacuum level. (a) Shows the entire spectra, and (b) shows expansion of the valence region.

Figure 4 displays the energy level diagram for the Ru dye adsorbed on $\mathrm{ZnO}$ nanorods. The known bandgap of $\mathrm{ZnO}$ (ca. $3.2 \mathrm{eV}$ [34]) has been used to establish the energy of the conduction band edge (CBE) relative to the valence band edge (VBE). However, it is concluded from Figure 4 that the LUMO edge is located $0.4 \mathrm{eV}$ below the $\mathrm{ZnO} \mathrm{CBE}$. The energy of the most populated vibrational excited state may be estimated by adding the maximum of the UV-vis absorbance spectrum for the MLCT transition to the HOMO energy. This places it $3.8 \mathrm{eV}$ below the vacuum level, which is slightly below the $\mathrm{ZnO} \mathrm{CBE}$.

Asbury et al. [35] have discussed factors that influence efficient electron transfer from an adsorbed dye's excited state to nanocrystalline semiconductor thin films. The enthalpic driving force and injection rate generally increase as the energy difference between

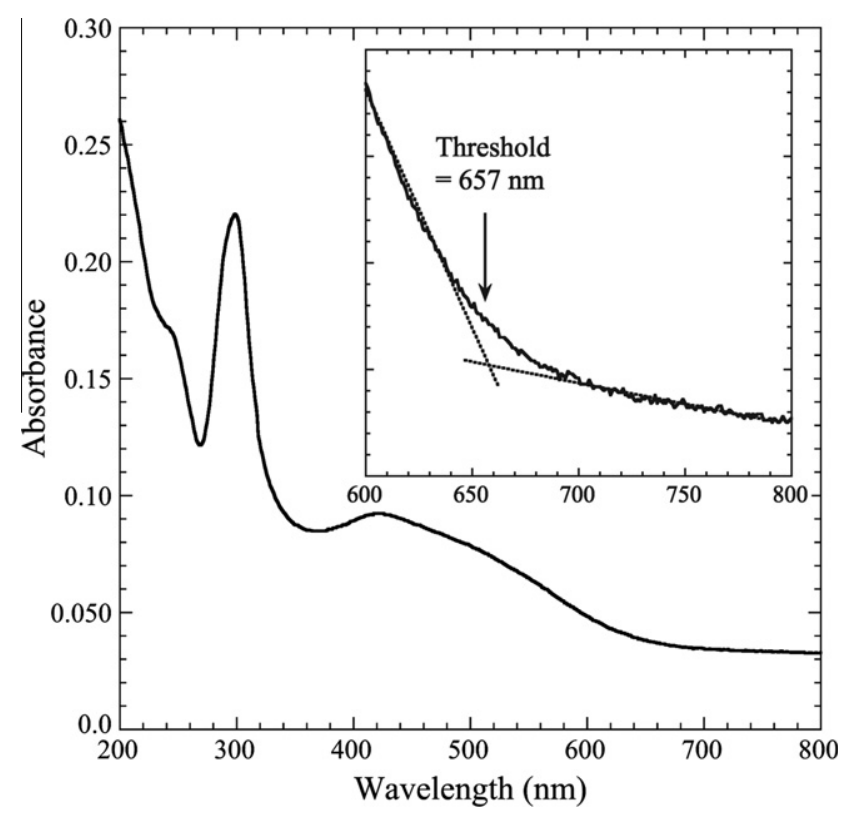

Figure 3. UV-vis absorbance spectrum of a spin-coated film of the Ru dye on a quartz substrate. A similar quartz substrate was used as the reference. The inset shows expansion of the long wavelength threshold region.

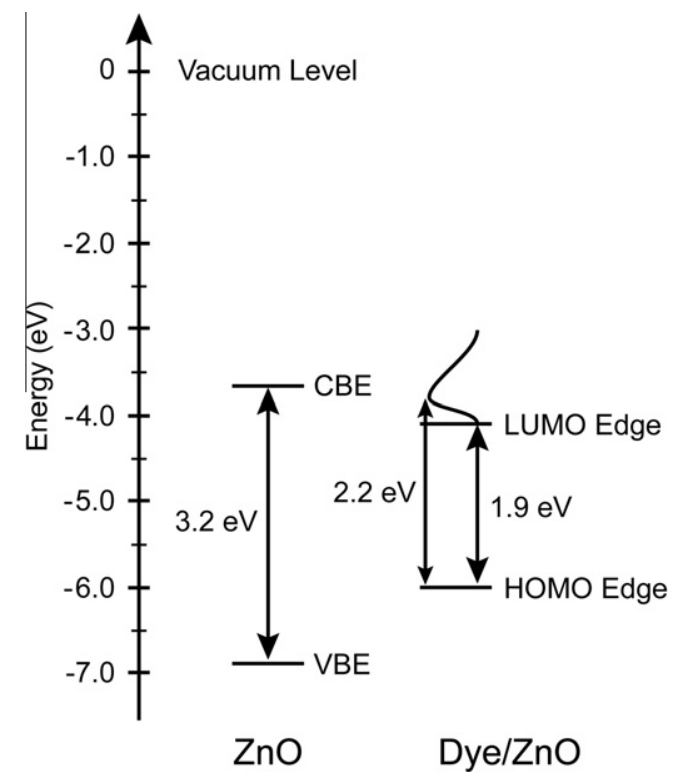

Figure 4. Energy level diagram obtained by combining the UPS results with the known bandgap of $\mathrm{ZnO}$ and the HOMO-LUMO gap of the Ru dye, estimated from the UV-vis spectrum. A depiction of the LUMO and its estimated position is included.

the adsorbate excited state and the CBE increases. The benchmarks for DSSC performance are devices made from $\mathrm{TiO}_{2}$ functionalized with the Ru dye 'N3'. Alignment of its LUMO with the $\mathrm{TiO}_{2} \mathrm{CBE}$ has been the subject of several investigations [25,29,35-37], and the LUMO peak (comprised of vibrational levels of the ligand $\pi^{*}$ electronic state) is believed to be at least several tenths of an $\mathrm{eV}$ above the $\mathrm{CBE}$.

Ohlsson et al. [24] measured the photoelectrochemical performance of the thiol-derivatized dye on $\mathrm{ZnO}$ and noted that, while it exhibited photon-to-charge carrier conversion, its performance was less than that of other dyes evaluated. The present study suggests that alignment of the LUMO peak with the CBE provides less 
enthalpic driving force for electron injection compared to N3 on $\mathrm{TiO}_{2}$. However other factors contribute to the efficiencies of DSSCs, including energy level matching between the dye and redox couple, electron transport through the photoelectrode, and back-transfer [38] from the electrode to the dye. Another factor may be the weak molar absorptivity of this dye [24]. Jose et al. [39] have also shown that the spatial proximity of the LUMO of the dye to the anchoring groups affects injection efficiency. Therefore, it is possible that less than optimal spatial overlap is also a factor.

While the dye studied in this Letter is not optimal for DSSC performance, these experiments indicate that thiol linkages are suitable candidates for covalently attaching $\mathrm{Ru}$ dyes to $\mathrm{ZnO}$ electrodes. The large packing density suggests that tuning of the electronic structure of the LUMO of the dye, such that it is at higher energy than the CBE of the $\mathrm{ZnO}$ particles and located on the thiol groups, would result in competitive DSSC performance.

\section{Conclusions}

This Letter demonstrates that thiol-derivatized Ru-based dyes chemisorb on $\mathrm{ZnO}$ electrodes via the formation of $\mathrm{Zn}-\mathrm{S}$ bonds. The packing density is sufficiently high to warrant serious consideration of this surface functionalization for practical devices. However, overlap of the dye's LUMO with the $\mathrm{ZnO}$ conduction band, for the particular dye evaluated, is not optimized for photovoltaic performance. Because of the possible benefits of $\mathrm{ZnO}$ as an alternative to $\mathrm{TiO}_{2}$ electrodes, it is worthwhile to pursue the design and synthesis of other thiol-functionalized dyes for DSSC applications. Experimental and theoretical studies in our laboratories are underway to investigate other thiol-functionalized Ru dyes and to evaluate the relative importance of effects such as the proximity of the LUMO of the dye to the thiol groups.

\section{Acknowledgements}

This work was supported by the US Army Natick Soldier Research, Development and Engineering Center under Contract \#W911NF-07-D-0001-0335 TCN 08047. Jagdeep Singh acknowledges a Tripathy Summer Fellowship. This document has been approved for unlimited distribution (PAO \#U09-505).

\section{References}

[1] H. Hoppe, N.S. Sariciftci, Adv. Polym. Sci. 214 (2008) 1.

[2] Y. Liang, D. Feng, Y. Wu, S.-T. Tsai, G. Li, C. Ray, L. Yu, J. Am. Chem. Soc. 131 (2009) 7792.
[3] M. Grätzel, Acc. Chem. Res. 42 (2009) 1788.

[4] M. Grätzel, J. Sol-Gel Sci. Technol. 22 (2001) 7.

[5] M. Grätzel, Inorg. Chem. 44 (2005) 6841.

[6] N. Robertson, Angew. Chem. Int. 45 (2006) 2338.

[7] H. Rensmo, K. Westermark, S. Södergren, O. Kohle, P. Persson, S. Lunell, H. Siegbahn, J. Chem. Phys. 111 (1999) 2744.

[8] A.S. Polo, M.K. Itokazu, N.Y.M. Iha, Coord. Chem. Rev. 248 (2004) 1343.

[9] S.Y. Huang, G. Schlichthörl, A.J. Nozik, M. Grätzel, A.J. Frank, J. Phys. Chem. B 101 (1997) 2576.

[10] G. Liu, W. Jaegermann, J. He, V. Sundström, L. Sun, J. Phys. Chem. B 106 (2002) 5814.

[11] R. Jose, V. Thavasi, S. Ramakrishna, J. Am. Ceram. Soc. 92 (2009) 289.

[12] T.P. Chou, Q. Zhang, G. Cao, J. Phys. Chem. C 111 (2007) 18804.

[13] P.W. Sadik, S.J. Pearton, D.P. Norton, E. Lambers, F. Ren, J. Appl. Phys. 101 (2007) 104514

[14] J. Dvorak, T. Jirsak, J.A. Rodriguez, Surf. Sci. 479 (2001) 155.

[15] N.S. Pesika, Z. Hu, K.J. Stebe, P.C. Searson, J. Phys. Chem. B 106 (2002) 6985.

[16] M.A. Garcia et al., Nano Lett. 7 (2007) 1489.

[17] M.-W. Tsao, J.F. Rabolt, H. Schonherr, D.G. Castner, Langmuir 16 (2000) 1734.

[18] J. Hedberg, C. Leygraf, K. Cimatu, S. Baldelli, J. Phys. Chem. C 111 (2007) 17587.

[19] B. Halevi, J.M. Vohs, Surf. Sci. 602 (2008) 198.

[20] J. Singh, J. Im, J.E. Whitten, J.W. Soares, D.M. Steeves, Langmuir 25 (2009) 9947.

[21] J. Singh, J. Im, J.E. Whitten, J.W. Soares, A. Meehan, D.M. Steeves, Proc. SPIE 7030 (2008) 70300T-1.

[22] Q. Wang, Q. Sun, P. Jena, J. Chem. Phys. 129 (2008) 164714

[23] O. Taratula et al., J. Phys. Chem. B 110 (2006) 6506.

[24] J. Ohlsson, H. Wolpher, A. Hagfeldt, H. Grennberg, J. Photochem. Photobiol. A 148 (2002) 41.

[25] J.H. Snook, L.A. Samuelson, J. Kumar, Y.-G. Kim, J.E. Whitten, Org. Electr. 6 (2005) 55.

[26] H. Ahn, M. Kim, D.J. Sandman, J.E. Whitten, Langmuir 19 (2003) 5303.

[27] L. Kavan, M. Grätzel, S.E. Gilbert, C. Klemenz, H.J. Scheel, J. Am. Chem. Soc. 118 (1996) 6716.

[28] E.M.J. Johansson et al., Chem. Phys. Lett. 464 (2008) 192.

[29] H. Zabri, I. Gillaizeau, C.A. Bignozzi, S. Caramori, M.-F. Charlot, J. Cano-Boquera, F. Odobel, Inorg. Chem. 42 (2003) 6655

[30] C.-Y. Chen, H.-C. Lu, C.-G. Wu, J.-G. Chen, K.-C. Ho, Adv. Funct. Mater. 17 (2007) 29.

[31] F. De Angelis, S. Fantacci, A. Selloni, Nanotechnology 19 (2008) 424002.

[32] H. Ishii, K. Seki, Energy level alignment at organic-metal interfaces, in: W.R. Salaneck, K. Seki, A. Kahn, J.J. Pireaux (Eds.), Conjugated Polymer and Molecular Interfaces, Marcel Dekker, New York, 2002, p. 293 (see also references therein).

[33] C. Shen, A. Kahn, I. Hill, Organic molecular interfaces: investigations of electronic structure, chemistry, and carrier injection properties, in: W.R. Salaneck, K. Seki, A. Kahn, J.J. Pireaux (Eds.), Conjugated Polymer and Molecular Interfaces, Marcel Dekker, New York, 2002, p. 351 (see also references therein).

[34] D.M. King, S.I. Johnson, J. Li, X. Du, X. Liang, A.W. Weimer, Nanotechnology 20 (2009) 195401.

[35] J.B. Asbury, E. Hao, Y. Wang, H.N. Ghosh, T. Lian, J. Phys. Chem. B 105 (2001) 4545.

[36] P. Persson, M.J. Lindqvist, J. Phys. Chem. B 109 (2005) 11918.

[37] G. Benkö, J. Kallioinen, J.E.I. Korppi-Tommola, A.P. Yartsev, V. Sundström, J. Am. Chem. Soc. 124 (2002) 489.

[38] R. Gaudiana, S. Hadjikyriacou, J.-A. He, D. Waller, Z. Zhu, J. Macromol. Sci. A 40 (2003) 1295

[39] R. Jose, A. Kumar, V. Thavasi, K. Fujihara, S. Uchida, S. Ramakrishna, Appl. Phys. Lett. 93 (2008) 023125 